\title{
Epidemiology of Leishmaniasis in Ecuador: Current Status of Knowledge - A Review
}

\author{
Manuel Calvopina/*/+, Rodrigo XArmijos*/**, Yoshihisa Hashiguchi
}

\author{
Department of Parasitology, Kochi Medical School, Kochi University, Kochi 783-8505, Japan *Unidad de Inmunologia y \\ Medicina Tropical, Centro de Biomedicina, Universidad Central del Ecuador, Quito, Ecuador **Health Sciences Program, \\ College of Health Sciences, University of Texas at El Paso, El Paso, TX, US
}

Although leishmaniasis is regarded as a significant health problem in Ecuador by the Ministry of Health, and the incidence has increased over the last years, an official map on the geographic distribution of disease and sand fly vectors or a control strategy do not exist yet. This article reviews the current situation based on published information to improve our knowledge and understand the epidemiological situation of leishmaniasis in Ecuador in order to help future research and to develop a national control strategy. The disease is endemic in most provinces throughout Pacific coastal region, Amazonian lowlands, and some inter-Andean valleys with a total 21,805 cases reported during 1990-2003. Whereas cutaneous leishmaniasis (CL) is found throughout Ecuador, mucocutaneous leishmaniasis (MCL) appears to be restricted to the Amazon region; one, parasitologically unconfirmed case of visceral form was reported in 1949. Most human infections are caused by Leishmania (Viannia) spp., which is distributed in the subtropical and tropical lowlands; infections due to L. (Leishmania) spp. are found in the Andean highlands and in the Pacific lowlands as well. The proven vectors are Lutzomyia trapidoi and Lu. ayacuchensis. Canis familiaris, Sciurus vulgaris, Potos flavus, and Tamandua tetradactyla have been found infected with Leishmania spp. It is estimated that around 3000-4500 people may be infected every year, and that 3.1 to 4.5 millions people are estimated to be at risk of contracting leishmaniasis.

Key words: leishmaniasis - Leishmania - epidemiology - Ecuador - review

Ecuador is located in north-west South America and straddles both the line of the Equator and the Andes mountain range (Fig. 1). The Andes cross the country from North to South and divide it into three different natural regions: the Pacific coast with subtropical and tropical lowlands, the Andean region with high mountains and valleys where temperatures range from 15 to $22^{\circ} \mathrm{C}$ and, in the East, a region which encompasses a section of Amazon lowlands covered by humid tropical rain forest. Ecologically, Ecuador is an extremely diverse country with a total area of $283,560 \mathrm{~km}^{2}$, ranging from tropical to nival (permanent snow) and from the rainforest to desert brush. The total population is $12,156,600$ inhabitants, of which $6,053,987$ live in the Pacific coast, 5,458,313 in the Andean region and 547,047 in the Amazon region; the remaining in the Galapagos Islands (Census 2001).

\section{HISTORICAL BACKGROUND}

Ancient representations of skin lesions and facial deformities have been found on pre-Inca pottery from Peru, Colombia, and Ecuador, estimated to date from AD 400 to AD 900. According Ecuadorian ceramics, cutaneous (CL) and mucocutaneous (MCL) leishmaniasis has existed for hundreds or perhaps thousands of years before the arrival of the Spanish conquerors. Historians at the time of the conquerors wrote of skin lesions seen among the Inca

\footnotetext{
+Corresponding author. Fax: +81-88-8802617/+81-88-8802415. E-mail: mcalvopina@hotmail.com

Received 27 April 2004

Accepted 14 July 2004
}

Indians which resulted in mutilations similar to those of some human figures (huacos) (Ala-Vedra 1952). The first human case of CL in Ecuador was reported in 1920 (Rodriguez 1974). Hashiguchi and Gomez (1991) have published a detailed description of chronological events associated with leishmaniasis up to 1987.

\section{THE GEOGRAPHICAL DISTRIBUTION AND INCIDENCE RATES OF HUMAN INFECTIONS}

Human leishmanial infections have been reported from 20/22 of the country's provinces (Fig. 1). Cases are recorded from sea level up to approximately $2700 \mathrm{~m}$ elevation, mainly from rural areas. An endemic belt is formed along the western slopes of the Andes involving new settlements in Imbabura, Pichincha, Cotopaxi, Bolivar, and Cañar provinces. CL and MCL forms had been recorded from all 6 Amazonian provinces (Amunarriz 1991). Since 1986 Ecuadorian Andean leishmaniasis has been reported from valleys of Paute (2300-2500 m), Alausi (2300-2700 m), and Huigra (1200-1500 m).

Fig. 2 shows the incidence of tegumentary leishmaniasis for the past 14 years as reported by the Ecuadorian Ministry of Public Health, based on passive case detection. However, this is probably an underestimate as patients consult private practitioners and non-governmental organizations (NGOs); also, CL can self-heal and, thus, these cases are not recorded. As noted in the Fig. 2, the average annual number of cases for the three geographical regions is 1558 (range: 531-3610). Given the differences in population size, the highest incidence rate is found in the Pacific region. The number of cases decreased steadily during the 1990s but suddenly increased in the last four years, with more than $75 \%$ of cases occurring in the Pa- 


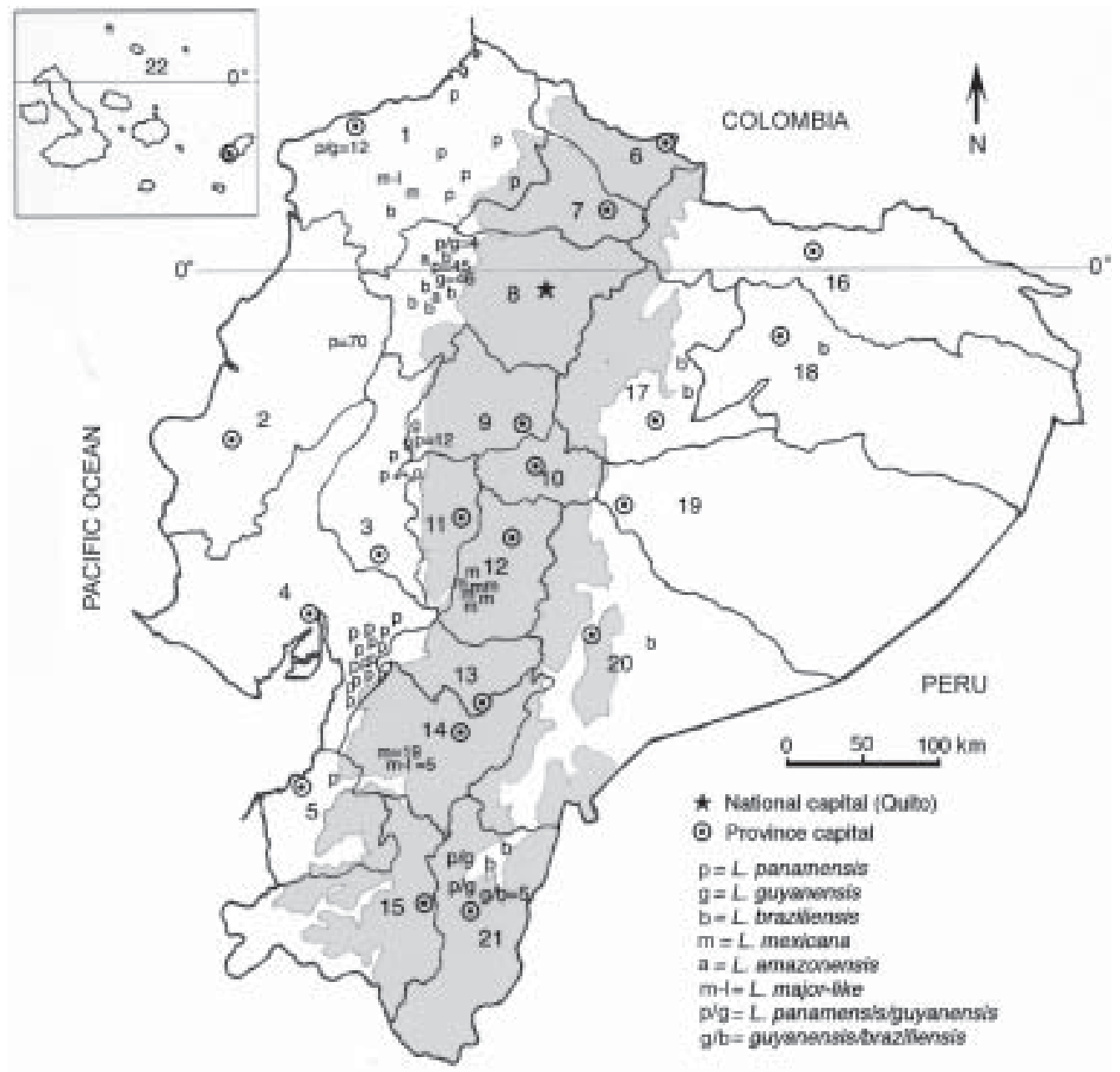

Fig. 1: map of Ecuador. The distribution of leishmaniasis by regions and provinces are showed with the respective numbers of Leishmania species identified (total 270 stocks). The disease is absent in Galapagos Islands and Carchi province. Shaded area indicates the Andean region with elevations > $1000 \mathrm{~m}$ above sea level. Provinces are identified by number: Esmeraldas (1), Manabi (2), Los Rios (3), Guayas (4), El Oro (5), Carchi (6), Imbabura (7), Pichincha (8), Cotopaxi (9), Tungurahua (10), Bolivar (11), Chimborazo (12), Cañar (13), Azuay (14), Loja (15), Sucumbios (16), Napo (17), Orellana (18), Pastaza (19), Morona Santiago (20), Zamora Chinchipe (21), and Galapagos (22)

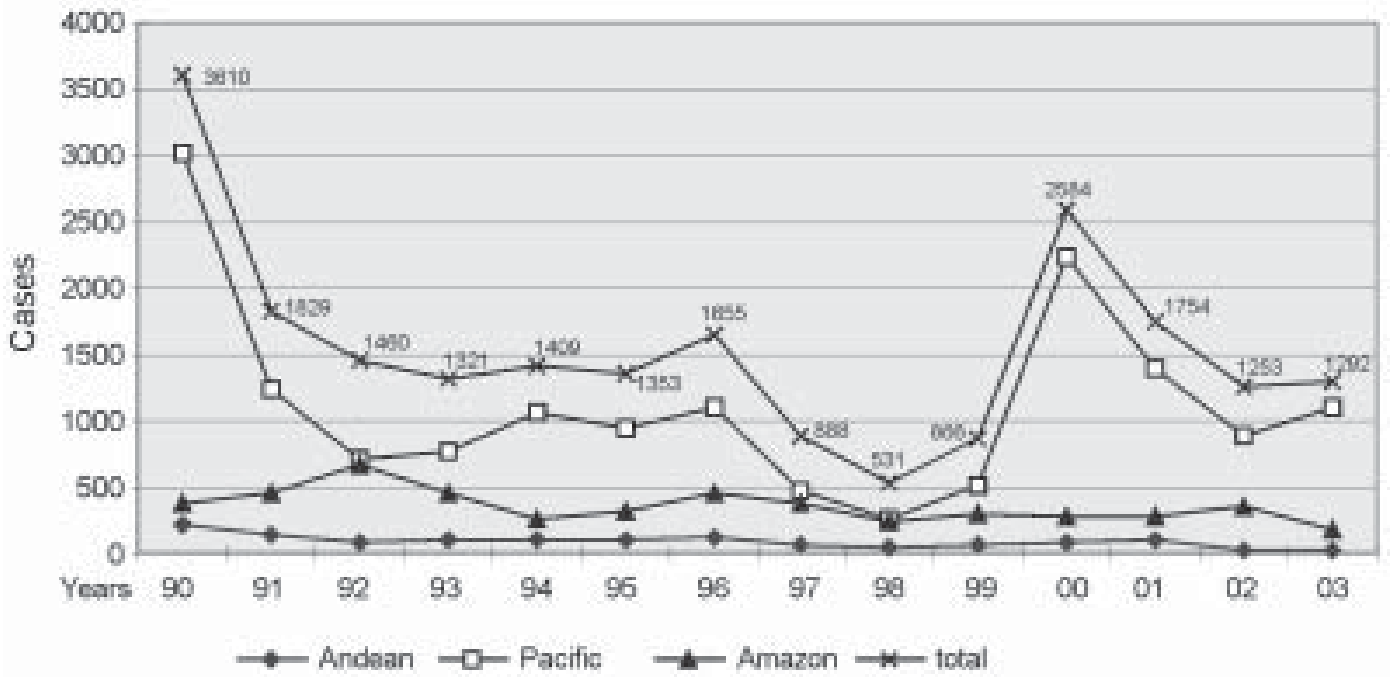

Fig. 2: the incidence rates region by region and the total cases from 1990-2003 
cific region. As in other leishmaniasis-endemic areas throughout Latin America, this increase may be attributed to changes in land use, the construction of new dams and human activity patterns like internal migration, leading to increase exposure of humans to the zoonotic Leishmania life cycles (Desjeux 2001). The decline and the increase of numbers of cases could be due to the frequency of the El Niño Southern Oscillation in Ecuador, but there are no evidences (Davies et al. 2000). Despite, the official epidemiological data showing that the disease prevalence has been decreasing in the last decade, active case detection studies have shown an increase in case numbers in several provinces (Alava et al. 1992, Barrera et al. 1994, Garcia et al. 1997, Nonaka et al. 1997). In fact, Armijos et al. (1997) and Hashiguchi et al. (1987) have reported that 14\% (65/466) and 7.5\% (7/93) of subjects surveyed in a subtropical rainforest area and Andean slope of Ecuador had CL, respectively. The incidence of leishmaniasis is expected to remain stable or increase in the near future due to the large number of previously unexposed groups such as young children and persons who visit (e.g., tourists) or move from non-endemic areas (e.g., agriculturalist, lumberjacks, workers for petrol exploitation, and subsequent colonization).

\section{ATTITUDES OF THE LOCAL POPULATION TO LEISH- MANIASIS}

Most adults from leishmaniasis-endemic areas of NW Ecuador are familiar with the disease and believe that it has a negative impact on the capacity to perform normal work duties and it needs some type of intervening treatment (Weigel et al. 1994, Weigel \& Armijos 2001). However, few knew about the transmission, etiology, ulcer healing, and conventional treatment. Women appeared to be more aware of the disease and scars because of the associated stigmatization of people affected. In the Amazon foci, because of tissue destruction and mutilation in the mucocutaneous form, patients tend to be isolated by the family and friends causing psychosocial impact with social and economic consequences (Amunarriz 1991). These local perceptions should be considered when planning future control programs and would be helpful to establish the communication channels that would be most effective with respect to control activities (e.g., identification of target groups). However, studies on people's knowledge, attitudes, and practices towards leishmaniasis do not exist in the Andean and Amazon regions. Certainly, the popular ideas and cultural practices in other foci might be different because of clinical presentation, cultural background, level of education, and environment between Amerindians in the Amazon and mestizo in the Andes foci. Further, plants and ethnomedical inventory used for the Amerindians in the Amazon foci do not exist in other regions (Amunarriz 1991).

The popular name for leishmaniasis in Ecuador differs from region to region. In the Pacific it is called sarna brava (angry sore), charra brava (angry ulcer) or charra colombiana (Colombian ulcer). In the Amazon region as milliai caracha or ulcera brava (angry ulcer) for CL and lepra de montaña (mountain leprosy) for MCL, whilst in the Andes people refer to it as nigua de raton (mice chig- ger) or grano malo (bad sore). In all regions manta blanca (white blanket) is the popular name for the vector.

Traditional treatments are frequently used, especially by rural populations who often lack access to conventional treatment. For example, the use of traditional methods is reported to be as high as $70 \%$ in NW Ecuador (Weigel et al. 1994), and 100\% in the Amazon region (Amunarriz 1991), with up to 150 different anti-leishmanial therapies used. The therapies described included various indigenous plants, chemicals or petroleum-based products. Although widely used by the communities, their efficacy is largely anecdotal and has never been proven in a controlled study. Other treatments methods such as cauterization with hot metal objects, strong acids, tobacco ash, and heated wax are also frequently used. These often cause tissue burns and promote the development of secondary infections, lengthen the cure and leaving bigger and permanent scars worse than those caused by the leishmaniasis itself (Weigel et al. 1994, Weigel \& Armijos 2001).

\section{CLINICAL FORMS AND THEIR CAUSATIVE PARASITES}

The diseases occur in Ecuador in most of its recognized American tegumentary forms: CL, MCL, and diffuse cutaneous (DCL) leishmaniasis. The reported ratio of MCL:CL is low (1:13) (Hashiguchi \& Gomez 1991). The unique cases reported as visceral leishmaniasis (VL) and DCL came from Esmeraldas province. DCL case was caused by L. (L.) mexicana (Reyna et al. 1994). To date, no other case of VL has been recorded, since the only case reported by Leon in 1949 was not confirmed by parasite isolation; it probably was a misdiagnosis. This is supported by the apparent absence of L. chagasi/infantum parasites and their vectors in the country (Young \& Rogers 1984, Alexander et al. 1992).

The clinical features of CL are different between highland and lowland cases. "Andean type" occurs usually as single lesion, measuring less than $5 \mathrm{~mm}$ in diameter; most of them are crusted papules with plenty parasites, and reported to be caused only by $L$. (L.) mexicana and $L$. (L.) major-like (Armijos et al. 1990, Hashiguchi et al. 1991). The lesions here are clinically similar to "uta" described in the highlands of Peru; however the parasite species and the vector are different (Lainson 1983). Whereas "lowland type" is larger, usually wet with secondary bacterial infection and multiple lesions.

Commonly, CL lesions are ulcerative, but non-ulcerated such as papules, plaques, nodules, and erysipeloid forms are also seen (Chico \& Guderian 1989, Nonaka et al. 1990, Armijos et al. 1997).

In the lowlands, cases of sporotrichoid or "pian-bois" form and the chiclero's ulcer have also been diagnosed and to be caused by L. (V.) guyanensis and panamensis (Armijos RX unpublished data). Six cases of leishmaniasis recidiva cutis (LRC), a cutaneous variant characterized for reactivations in old scars, and two patients having dozens of cutaneous ulcers described as disseminated leishmaniasis are reported from the Pacific region, the causative agent was identified to be $L$. (V.) panamensis (Lazo \& Hashiguchi 1994, Calvopina et al. 2004). Recently, in an active survey for MCL in the Amazonian provinces of 
Sucumbios, Orellana, and Napo we encountered 13 active cases of MCL caused by L. (V.) braziliensis (Calvopina et al. 2001a), suggesting that this form and parasite could be prevalent in this humid tropical forest. MCL originating from the Pacific or Andean regions has never been recorded (Hashiguchi et al. 1991, Barrera et al. 1994, Armijos et al. 1997). This is surprising, as Osorio et al. (1998) reported MCL among residents of the Colombian Pacific coast caused by the same species circulating in this Ecuadorian region.

\section{PARASITE DISTRIBUTIONS}

Currently, six Leishmania spp. have been identified from humans, sand flies and non-human mammals (Table). The map (Fig. 1) shows the distribution of identified species by regions and provinces. Findings are that the ratio of $L$. (Viannia) to L. (Leishmania) infections is about 6:1. Clearly, L. (V.) panamensis and guyanensis are predominant in the subtropical and tropical lowlands of the $\mathrm{Pa}-$ cific region (62.1\% of all). Recently, Bañuls et al. (1997, 1999) doubted the separate taxonomic status of the latest two species. $L$. (L.) amazonensis has been only reported from subtropical Ecuador in human CL (Armijos et al. 1990, Furuya et al. 1997), but also infecting other mammals (Mimori et al. 1989). Notoriously, L. (V.) braziliensis is geographically the species most widespread in the country, having been isolated from CL and MCL patients in nine of 15 surveyed provinces (Armijos et al. 1990, 1997, Bañuls et al. 1999, Furuya et al. 1997, Calvopina et al. 2001a). In the Amazon region only L. (V.) braziliensis was identified, but hybrid genotypes between $L$. $(V$.) panamensis/guyanensis and $L$. (V.) braziliensis had also been reported (Bañuls et al. 1997). Furthermore, Pratlong et al. (2002) identified $L$. naiffi in a German patient with CL suspected to be infected in this region.

For Andean leishmaniasis the parasite is reported to belongs only to the subgenus Leishmania: L. mexicana for $82.4 \%$ (28/34) and L. major-like (Armijos et al. 1990, Hashiguchi et al. 1991), where lesions resembled to "uta" of Andean valleys of Peru; but the causative agent there is identified as L. (V.) peruviana (Lainson et al. 1983) hence, further studies with a standardized methodology have to be established in order to enable comparisons between both foci. L. major-like parasite had also been reported from Brazil, Paraguay, Venezuela, and Mexico (Cupolillo et al. 1994, Yamasaki et al. 1994) suggesting that some of these populations may have been imported into the Americas (Momen et al. 1993). The nucleotide sequences of cytochrome $b$ of $L$. major-like isolated from the Ecuadorian Andes and the WHO reference strain $L$. major had a 99.9\% homology (Luyo-Acero et al. 2004).

Parasite isolates from a sloth (Choloepus hoffmani) and a squirrel (Sciurus granatensis) caught in tropical forest of the Pacific region characterized before as $L$. (V.) equatorensis (Grimaldi et al. 1992), actually Uezato et al. (2001) and Katakura et al. (2003) using molecular methods identified that it belongs to the genus Endotrypanum spp.

Since a small proportion of all leishmaniasis cases are ever diagnosed to species level, with a total of 270 cases from nine surveys, further studies are needed in order to isolate and identified the parasites circulating in most provinces reporting the disease.

TABLE

Distribution of Leishmania parasites in humans, vectors, and putative reservoir hosts by regions in Ecuador

\begin{tabular}{|c|c|c|c|c|c|}
\hline $\begin{array}{l}\text { Parasite } \\
\text { identified }\end{array}$ & $\begin{array}{l}\text { Characterization } \\
\text { methods }\end{array}$ & $\begin{array}{l}\text { Clinical } \\
\text { forms }\end{array}$ & Vectors & $\begin{array}{l}\text { Reservoir } \\
\text { hosts }\end{array}$ & References \\
\hline \multicolumn{6}{|l|}{ Pacific region } \\
\hline L. (V.) panamensis & $\mathrm{IE}, \mathrm{mAb}$ & LCL, LRC,DL & Lu. trapidoi & Canis familiaris & AR,MT,LeP,DE,CM,FM \\
\hline L. (V.) guyanensis & IE & LCL & Lu. trapidoi & NI & $\mathrm{AR}, \mathrm{BA}$ \\
\hline L. (V.) panam/guyan & IE, RAPD & LCL & Lu. trapidoi & Canis familiaris & $\mathrm{BA}$ \\
\hline L. (V.) braziliensis & $\mathrm{IE}, \mathrm{mAb}$ & LCL & NI & NI & $\mathrm{AR}, \mathrm{BA}, \mathrm{FM}$ \\
\hline L. (L.) amazonensis & IE, mAb, kDNA & LCL & NI & $\begin{array}{l}\text { Sciurus vulgaris, } \\
\text { Potos flavus \& } \\
\text { Tam. tetradactyla }\end{array}$ & AR, MT, FM \\
\hline L. (L.) major-like & IE, kDNA & LCL & NI & NI & HY \\
\hline L. (L.) mexicana & IE, kDNA & LCL, DCL & NI & NI & $\mathrm{RE}$ \\
\hline \multicolumn{6}{|l|}{ Andean region } \\
\hline L. (L.) mexicana & IE, mAb, kDNA & LCL & Lu. ayacuchensis & Canis familiaris & AR, HY, FM \\
\hline L. (L.) major-like & $\mathrm{IE}, \mathrm{mAb}, \mathrm{kDNA}$ & LCL & $\mathrm{NI}$ & $\mathrm{NI}$ & HY, FM \\
\hline \multicolumn{6}{|l|}{ Amazon region $^{a}$} \\
\hline L. (V.) braziliensis & IE, mAb, PCR & LCL, MCL & NI & NI & AR, CM, FM \\
\hline L. (V.) brazil/panam-guyan & IE, RAPD & LCL & Lu. serrana ${ }^{b}$ & NI & LeP, BA \\
\hline
\end{tabular}

a: Lutzomyia spp. identified in Orellana province but negative for Leishmania: Lu. tortura, flaviscutellata, olmeca bicolor, gomezi, carrerai thula, geniculata and yuilli yuilli (Calvopina et al. 2001a). In Zumba-Zamora Chinchipe province: Lu. maranonensis, serrana, and castanea (Le Pont et al. 1994); Lu. serrana, nevesi, and strictivilla (Alexander et al. 1992); b: suspected vector. Characterization methods - IE: isoenzyme electrophoresis; mAb: monoclonal antibodies; k-DNA: kinetoplast DNA schizodeme analysis; PCR: polymerase chain reaction; RAPD: random amplified polymorphic DNA; NI: not identified. Clinical forms - LCL: localized cutaneous; LRC: leishmaniasis recidiva cutis; DCL: diffuse cutaneous; MCL: mucocutaneous; DL: disseminated leishmaniasis. References: AR (Armijos et al. 1990, 1997), CM (Calvopina et al. 2001a), DE (Dereure et al. 1994), FM (Furuya et al. 1997, 1998), HY (Hashiguchi et al. 1991), LeP (LePont et al. 1994), MT (Mimori et al. 1989, 1990), RE (Reyna et al. 1994), BA (Bañuls et al. 1997, 1999) 


\section{AGE, GENDER, AND BODY DISTRIBUTION OF LESIONS}

The age groups affected differ from region to region. In the Andean foci the most affected are children under two years, suggesting indoor-transmission and probably dogs as reservoirs (Hashiguchi et al. 1991). In the lowlands are children under the age of ten in tropical and five years in subtropical Pacific region (Alava et al. 1992, Armijos et al. 1997). The increased disease prevalence in children could be associated with no previous exposure to the parasite, the role of cellular immune status and/or with malnutrition (Weigel et al. 1995). Nevertheless, for the Amazon region in a passive hospital-based report the mean age of leishmaniasis diagnosis was 33.4 and 19.7 years for MCL and CL respectively (Amunarriz 1991), suggesting unknown reasons for delays in the diagnosis in this wide and disperse region. However, it is also evident that exposure to transmission at any age as do immigrants or tourists they will develop the disease.

No gender difference in the incidence is observed among children at any endemic regions surveyed (Hashiguchi et al. 1991, Weigel et al. 1994). However, the sex difference regarding disease prevalence in the adult population appears to be important. Thus, in the Amazon region a passive hospital-based reported $81 \%$ (22/27) of MCL and 83\% (67/81) of CL cases to be male (Amunarriz 1991); Calvopina et al. (2001a) also encountered 85\% (11/ 13) of MCL in male. Hence, the excess risk observed in this region is for male older than 14 years suggesting that it could be associated with their occupational exposure (i.e., hunting and agricultural work) characteristic of sylvatic transmission cycle of Leishmania. In a communitybased study in the subtropical of Pacific region adult male had a disease risk almost three times greater than of adult female (Weigel et al. 1994). But, several years after in the same study area, no differences were observed (Weigel \& Armijos 2001) changes here appeared to be associated with change from sylvatic to domestic and peridomiciliary transmission.

Lesions are most frequent on the exposed parts of the body. The children face is more frequently affected (92\%) in the Andean foci (Hashiguchi et al. 1990), probably because mother's cultural behavior in taking care small children in this cool region and where probably indoor-transmission occur. Whilst, in the lowlands, lesions or scars are mostly in the extremities (53.8 to 92\%), it is hypothesized because of difference of biting behaviors of sand flies or clothing habits of inhabitants in hot climate (Amunarriz 1991, Alava et al. 1992, Armijos et al. 1997). Chiclero's ulcer is not rare in lowlands foci. Other sites affected include the trunk and, less commonly the scalp, buttocks, eyelids, and genitalia. MCL affects the nasal mucosa, septum and turbinate, upper lip, pharynx and larynx producing dyspnoea, and face deformities (Calvopina et al. 2001a).

\section{VECTORS}

The Table lists the sand fly species incriminated as vectors of Leishmania in Ecuador. More than 60 species of phlebotomine sand flies, including 55 species belonging to the genus Lutzomyia have been described (Young \& Rogers 1984, Alexander et al. 1992). At least 15 Lutzomyia spp. are known to be anthropophilic and are strongly suspected as vectors. Natural infection with promastigotes morphologically identical to Leishmania have been observed but not characterized in Lu. gomezi, hartmanni and panamensis. In the Pacific region, Lu. trapidoi, a proved vector here, is more abundant in the dry season whilst Lu. gomezi in the wet season (Le Pont et al. 1994a,b). Dujardin et al. (1996) demonstrated the presence of cryptic species in Lu. trapidoi. Studies carried out in 1982 (Hashiguchi et al. 1985) and in 1993 (Furuya et al. 1998) in this region, demonstrated that in 1982 the predominant species was $L u$. trapidoi with $8.1 \%$ of flagellates in their hindgut, but 10 years later $L u$. hartmanni predominate with $9.8 \%$ of infection. The latter species was recently confirmed to harbor Endotrypanum spp. (Uezato et al. 2001, Katakura et al. 2003), believed before to be $L$. (V.) equatorensis (Furuya et al. 1998).

For Andes foci, six anthropophilic Lutzomyia (ayacuchensis, hartmanni, nevesi, gomezi, serrana, and osornoi) have been identified so far (Gomez et al. 1994), with, only ayacuchensis shown to be naturally infected with L. (L.) mexicana (Hashiguchi et al. 1991). Lu. ayacuchensis abounds in the wet season and its infection rate is found to be highest during the period from the early rainy season to the beginning of the dry season (Gomez \& Hashiguchi 1991). It correlates with the appearance of new human cases. In these inter-Andean valleys, there is strong evidence that transmission of Leishmania occurs indoors and in urban settings (Hashiguchi et al. 1987, Armijos et al. 1990).

For the Amazon region, in the Zumba focus south wards of Ecuador bordering with Peru several man-biting species have been recorded, $L u$. serrana abounds inside dwellings where it even bite during daytime (Alexander et al. 1992, Le Pont et al. 1994c), suggesting this species as a candidate vector in an indoor-transmission manner. In the inter-Andean Ecuadorian-Peruvian border Lu. robusta was also described (Galati et al. 1995). Both species are suspected vectors of human bartonellosis as well, since there is no probed vector for Bartonella bacilliformis endemic in those areas (Cooper et al. 1996). From Orellana province seven anthropophilic species captured in MCL focus were identified but all negatives for natural infection (Calvopina et al. 2001a). In the whole country there are no reports on Lu. longipalpus and evansi a confirmed vectors of L. chagasi/infantum in the neighboring countries.

\section{PUTATIVE RESERVOIR HOSTS}

The Table lists the non-human mammals where Leishmania has been characterized. One Canis familiaris was found infected with $L$. (V.) panamensis or panamensis/ guyanensis and one with $L$. (L.) mexicana in the Pacific and in the Andes region, respectively (Dereure et al. 1994, Bañuls et al. 1999, Hashiguchi et al. 1991). Both reports are congruent with the human strains isolated in the respective regions. Sciurus vulgaris, Potos flavus, and Tamandua tetradactyla were found infected in the Pacific region with L. amazonensis (Mimori et al. 1989). Positive flagellate cultures from additional eight different mammalian species from the Pacific region have been grown, 
but were not characterized (Hashiguchi et al. 1985). No positive parasite isolation or detection has been done from putative reservoir hosts in the Amazon region.

Serological studies to examine the role of dogs in the leishmaniasis transmission cycle carried out in the interAndean valley of Alausi found 19/58 (32.8\%) of surveyed dogs positive for ELISA; no dog had positive liver-puncture aspirates (Mimori et al. 1992). Another study also showed high ELISA-rate positivity using antigens of $L$. (V.) panamensis and guyanensis in 12/17 dogs from Alausi and 12/20 from the Pacific region (Mori et al. 1994). These results showed high reactivity for ELISA but careful attention must be paid on the cross-reactivity (false-positives) where Trypanosoma cruzi is endemic as is in lowlands of Ecuador (Aguilar et al. 1999). The positive samples should be confirmed parasitologically and characterized, even that, it does not distinguish whether dogs are accidental or reservoir hosts, dogs seems to be a victim-host as humans are. Due to low specificity and sensitivity of the methods employed, the PCR-based method could show better results if it is carried out properly (Reithinger et al. 2000).

\section{DIAGNOSIS}

In endemic areas of Ecuador the diagnosis of leishmaniasis is generally based on clinical criteria, because few laboratories have the capacity of confirming and most of them are far from rural endemic areas. Specialized laboratories doing cultures, Montenegro skin test and/or PCR are rare and are restricted to research purposes. Microscopic examination of Giemsa-stained smears is the recommended method by the public health authorities. The examination, however, has shown to have a lower sensitivity than culture and PCR (Aviles et al. 1999, Matsumoto et al. 1999, Calvopina et al. 2001b). The sensitivity of smears and cultures decreased if lesions were chronic and due to microbial contamination. The rate of parasite isolation in MCL patients was low as $23 \%$, probably due to chronicity and scarcity of parasites in mucosal lesions (Calvopina et al. 2001a). Parasitological diagnosis is the "gold standard" in leishmaniasis, as it is highly specific (Davies et al. 2000). However, in laboratories from endemic areas of Ecuador there are many false positives on the microscopic examination of Giemsa-stained smears that might due to untrained staff. The direct immunofluorescent antibody (DIFMA) test showed higher sensitivity and rapidity superior to scraping, culture and histology (Chico et al. 1995). The histology staining showed the lowest sensitivities (Aviles et al. 1999, Calvopina et al. 2001b); given the limited utility and dear of histology, this method should be reserved for selected patients.

Recently, several studies in Ecuador have found PCRbased method to be more sensitive ( $85.4 \%$ on average) than classical diagnostic techniques, named slit smears (45.4\%), culture (57.2\%), and histopathology (34.7\%). In some way the sensitivity of PCR depended on the sample taken, from skin biopsies and exudates using cotton swabs it reached to $92 \%$ and $93.8 \%$, respectively (Aviles et al. 1999, Calvopina et al. 2001b, Mimori et al. 2002), but using scrape/exudates or syringe-sucked fluid the sensitivities decrease to $70 \%$ (Matsumoto et al. 1999). The before col- lection procedures should be validated on large samples. However, still a concern the false-negative rate showed by PCR that could be as high as $15.4 \%$ (Mat-sumoto et al. 1999). The employment of PCR allowed the identification of Leishmania at subgenus or complex level, but recently a study using polymorphism-specific primers yielded to identify species from clinical samples (Mimori et al. 1998). Other advantage of PCR is that diagnosis could be obtained on biopsy samples which are either in formalin or ethanol fixed and paraffin-embedded histological sections (Uezato et al. 1998, Mimori et al. 2002). Finding on PCR amplification of the Leishmania mini-exon gene and karyotype characterization suggest that it would be used for diagnosis and for molecular epidemiology in Ecuador (Katakura et al. 1993, 1998). Nevertheless, in Ecuador, PCR system still expensive, personnel well trained and a reference center to process the samples are still needed.

\section{DIFFERENTIAL DIAGNOSIS}

In Ecuador, the differential diagnosis of leishmaniasis includes a range of skin conditions, which depend on the prevailing disease pattern in the different leishmaniasisendemic regions. Similar to other endemic countries in Latin America, clinical diagnosis of leishmaniasis can be over-estimated in rural areas where appropriate tests to confirm lesion etiology are absent (Lopez et al. 1993, De Brujin et al. 1993, Calvopina et al. 2001b). In a hospitalbased survey Hosokawa et al. (2001) showed that 5/16 $(31.2 \%)$ were misdiagnosed as having $\mathrm{CL}$ and MCL and had been receiving anti-leishmanial drugs. The five misdiagnosed patients had basal cell carcinoma, chromomycosis and ulcus cruris varicosum. Other skin conditions commonly misdiagnosed as leishmaniasis were furuncle, Bazin's disease, liquen vulgaris, mycetoma, sporotrichosis, myasis, leprosy, and bacterial ulcers. MCL should be differentiated from paracoccidioidomycosis which is prevalent in the tropical lowlands of Ecuador (Fernandez 1990). Leprosy still endemic in rural Ecuador and because is overlapping leishmaniasis-endemic areas could make clinical confusions.

\section{TREATMENT}

In Ecuador, pentavalent antimonials are the first-line drugs recommended by the Ministry of Health, and indeed WHO; Glucantime ${ }^{\circledR}$ (meglumine antimoniate) is the only available drug and is delivered free of charge by the Ministry of Health, but it can be bought in pharmacies without medical prescription. There is shortage, however, every time principally in rural Ecuador where the disease is prevalent as was noted by Weigel et al. (1994). Some NGOs are also distributing the drug at a subsidized price. The recommended dose is $10-20 \mathrm{mg} \mathrm{Sb} / \mathrm{kg} / \mathrm{d}$ for $10-15$ days for $\mathrm{CL}$ and 28 days for MCL, by intramuscular injection. However, a significant proportion of patients fail to complete their full course of treatment because of the drug's side-effects and the lengthy painful course of treatment; a full treatment course is also expensive, i.e. US $\$ 5$ to 6 per ampoule. Thus, in an endemic CL subtropical area, where most of the adults are familiar with the disease, only $12 \%$ received a full course of Glucantime, while $7.5 \%$ got an incomplete course (Weigel et al. 1994). A follow-up 7 years 
after, the proportions of subjects who had used Glucantime remained low (20\%) while the premature drug discontinuance appeared to have doubled (Weigel \& Armijos 2001). Therefore, in order to monitor drug side-effects and responsiveness, it is not unusual for MCL patients to be hospitalized for two or three times (Amunarriz 1991). There is no available data on unresponsiveness to Glucantime but is frequently observed mainly in MCL cases and CL acquired in Amazonian lowlands, no study has been done on parasite resistance. The intralesional infiltration with Glucantime alone or combined with intramuscular injection is also popular in endemic areas and recommended for whom systemic chemotherapy is contraindicated. But, this method should not be applied in patients acquiring the infection in the Amazon region where L. (V.) braziliensis has the propensity to evolve into MCL. Second-line drugs (i.e. pentamidine and amphotericin B) are not available in the country.

Several clinical studies to test the efficacy of alternative anti-leishmanial drugs have been carried out in Ecuador. Guderian et al. (1991) tested allopurinol plus probenecid against CL, but only $9(41 \%)$ were healed, compared with $96 \%$ of Pentostam $®$ group and $75 \%$ healing rate for the placebo group. Nonaka et al. (1992) applied paromomycin (PM) ointment as a monotherapy showing to be rather ineffective against CL in the Pacific region with clinical cure in 10-54\% of patients. Krause and Kroeger (1994) using PM plus methylbenzethonium (MBCL) for CL in the Pacific region cured $85 \%$ with $9 \%$ healed spontaneously in the placebo control group, but their followup was only 50 days. Armijos et al. (2004) using topical PM-MBCL and PM-urea reach clinical cure in $79.3 \%$ and $70 \%$ respectively, by 12 weeks of follow-up. Looking for an oral treatment Gomez et al. (1997) administered mefloquine (Mephaquin $\AA$ ) and artesunate (Plasmotrim $®)$ to patients infected in the Pacific region, reporting cure rates of $100 \%$. However, studies in the Pacific of Colombia (Hendrickx et al. 1998) and in the state of Bahia of Brazil (Laguna-Torres et al. 1999) showed that cure rates with mefloquine were similar than for the placebo controls and less than half observed in the $\mathrm{Sb}(\mathrm{v})$ group. Itraconazole (Sporanox ${ }^{\circledR}$ ) was given orally at high dosage and for 90 days in 13 patients with MCL in the Amazon region, three patients were cured clinically and parasitologically, concluding that itraconazole is not longer effective in this clinical form (Calvopina et al. 2004). Nifurtimox (Lampit®) were administered in the Amazon region with apparently good results (Amunarriz 1991). Despite an uncontrolled study reporting cure rates of $100 \%$ using S-nitroso-Nacetylpenicillamine (SNAP), a compound that generates nitric-oxide (Lopez-Jaramillo et al. 1998), a subsequent study showed disappointing results in murine CL and in a clinical trial, showing low cure rate and a high rate of local reactions (Davidson et al. 2000).

The spontaneous healing of CL is common in patients infected in the Andean region, as well as in the subtropical Pacific region that can be as high as $75 \%$ (Hashiguchi et al. 1991, Guderian et al. 1991). Hence, patients been infected in the Andes foci usually should not be treated systemically because the lesions are small and self-heal within months leaving a small and imperceptible scar
(Hashiguchi et al. 1991) and because there is no risk of metastasis. However, recently leishmaniasis recidivans has been reported in the subtropical Pacific region, such patients should be treated adequately. Patients with severe, sporotrichoid type, multiple lesions (>3), diabetics and with lesions on the eyelid, the auricle of ear, face and nose which may cause disfiguring scars should also be treated promptly.

\section{PREVENTION AND CONTROL MEASURES}

Passive case finding and treatment is the only control measure followed in Ecuador with afore-mentioned limitations in sampling, diagnosis, drug availability, and training of medical staff. A vaccination trial with killed cocktail of promastigotes was conducted in the subtropical-Ecuador (Armijos et al. 1998) showing significant protection during the first 12 months $(72.9 \%)$. Protection declined until month 60 of follow-up, with no difference in protection rate between the vaccinated and placebo groups (Armijos et al. 2003). Another study was conducted in a similar endemic area using Leishvaccin ${ }^{\circledR}$ plus BCG adjuvant, although two doses of the vaccine resulted in a significant increase in Montenegro skin test conversion, it did not appear to offer any significant protection against development of CL compared to the placebo group (Armijos et al. 2004). As outlined here, further region-specific studies are required on the geographic distribution of disease, sandfly vectors, reservoirs hosts and risk factors in order to identify and develop a leishmaniasis intervention strategy that is cost-effective.

\section{CONCLUSIONS}

Though the knowledge on the geographical distribution and burden of leishmaniasis in Ecuador has increased over the last years, it is still incomplete and patchy. The situation on the structure of vector and reservoir system is limited. The national recording and reporting system even that is compulsory since 1985, is limited by gaps in information, usually quantitative, sometimes qualitative. As there is little accurate data on country specific prevalence, estimates for the number of people infected and number at risk of infection must still be made based on extrapolations of passive case detection prevalence. Glucantime is still not reaching the majority of those who most need it; delivery of drug should be supported in a comprehensive reporting and actualized data. Most of the studies had been done by private initiatives. Health authorities must be able to translate the actual knowledge into better information, education, and research in accordance with the endemic level, principally in their peripheral health system. In the future, would be important to design trials in order to clarify aspects like El Niño and its impact in annual fluctuation of the vector population as well as the impact of the global warming phenomenon. Imaginative research studies, adequate funds and infrastructure are urgently needed to define the disease epidemiology and to develop a national prevention and control strategy.

\section{ACKNOWLEDGEMENT}

To Richard Reithinger for his valuable comments. 


\section{REFERENCES}

Aguilar VHM, Abad-Franch F, Racines VJ, Paucar AC 1999. Epidemiology of Chagas disease in Ecuador. A brief review. Mem Inst Oswaldo Cruz 94 (Suppl. 1): 387-393.

Ala-Vedra y Tama 1952. El boton de Oriente en Ecuador, ulcera tropical, leishmaniosis Americana. I Jorn Ped Ecuat. Guayaquil, Ecuador, p.1-23.

Alava JJ, Mora AE, Gomez EA, Hashiguchi Y 1992. Studies on leishmaniasis in an endemic focus of Leishmania on the Pacific coast of Ecuador. In: Studies on New World Leishmaniasis and its Transmission with Particular Reference to Ecuador, Kochi, Japan. Res Rep Series 3: 59-69.

Alexander JB, Takaoka H, Eshita Y, Gomez EA, Hashiguchi Y 1992. New records of phlebotomine sand flies (Diptera: Psychodidae) from Ecuador. Mem Inst Oswaldo Cruz 87: 123-130.

Amunarriz M 1991. Leishmaniasis. In Estudios sobre Patologias Tropicales en la Amazonia Ecuatoriana, Cicame, Napo Ecuador, Cap. 3, p. 41-64.

Armijos RX, Chico M, Cruz M, Guderian R, Kreutzer R, Berman J, Rogers M, Grogl M 1990. Human cutaneous leishmaniasis in Ecuador: Identification of parasites by enzyme electrophoresis. Am J Trop Med Hyg 42: 424-428.

Armijos RX, Weigel MM, Aviles H, Maldonado R, Racines J 1998. Field trial of a vaccine against New World cutaneous leishmaniasis in an at-risk child population: Safety, immunogenicity, and efficacy during the first 12 month of follow-up. J Infect Dis 177: 1352-1357.

Armijos RX, Weigel MM, Calvopina M, Hidalgo A, Cevallos W, Correa J 2004. Safety, Immunogenecity, and efficacy of an autoclaved Leishmania amazonensis vaccine plus BCG adjuvant against New World cutaneous leishmaniasis. Vaccine 22: 1320-1326.

Armijos RX, Weigel MM, Romero L, Garcia V, Salazar J 2003. Field trial of a vaccine against New World cutaneous leishmaniasis in an at-risk child population: How long does protection last? J Infect Dis 187: 1959-1961.

Armijos RX, Weigel MM, Calvopina M, Mancheno M, Rodriguez R 2004. Comparison of the effectiveness of two topical paromomycin treatments vs meglumine antimoniate for New World cutaneous leishmaniasis. Acta Trop 91: 153160.

Armijos RX, Weigel MM, Izurieta R, Racines J, Zurita C, Herrera W, Vega M 1997. The epidemiology of cutaneous leishmaniasis in subtropical Ecuador. Trop Med Int Health 2: 140-152.

Aviles H, Belli A, Armijos RX, Monroy F, Harris E 1999. PCR detection and identification of Leishmania parasites in clinical specimens in Ecuador: A comparison with classical diagnostic methods. J Parasitol 85: 181-187.

Barrera C, Herrera M, Martinez F, Leon R, Richard A, Guderian RH, Mouchet J, Echeverria R, Le Pont F 1994. Leishmaniasis in Ecuador. 1. Incidence of cutaneous leishmaniasis on the Pacific coast. Ann Soc Belg Med Trop 74: 1-12.

Bañuls AL, Guerrini F, Le Pont F, Barrera C, Espinel I, Guderian R, Echeverria R, Tibayrenc MJ 1997. Evidence for hybridization by multilocus enzyme electrophoresis and random amplified polymorphic DNA between Leishmania brasiliensis and L. panamensi/guyanensis in Ecuador. J Euk Microbiol 44: 408-411.

Bañuls AL, Jonquieres R, Guerrini F, Le Pont F, Barrera C, Espinel I, Guderian R, Echeverria R, Tibayrenc M 1999. Genetic analysis of Leishmania parasites in Ecuador: Are Leishmania (Viannia) panamensis and L. (V.) guyanensis distinct taxa? Am J Trop Med Hyg 6: 838-845.

Calvopina M, Guevara A, Gomez EA, Paredes W, Mimori T,
Guderian R, Nonaka S, Hashiguchi Y 2001b. Diagnosis of cutaneous leishmaniasis with PCR technique in comparision with conventional methods. In Studies on New World Leishmaniasis and its Transmission with Particular Reference to Ecuador. Kochi, Japan. Res Rep Series 6: 49-57.

Calvopina M, Guevara AG, Armijos RX, Hashiguchi Y, Davidson $\mathrm{R}$, Cooper P 2004. Itraconazole in the treatment of New World mucocutaneous leishmaniasis. Inter J Dermatol (in press).

Calvopina M, Guevara A, Armijos R, Gomez EA, Mimori T, Cooper P, Hashiguchi Y 2001a. Clinical features of mucocutaneous leishmaniasis in the Amazonian region of Ecuador. In Studies on New World Leishmaniasis and its Transmission with Particular Reference to Ecuador. Kochi, Japan. Res Rep Series 6: 82-89.

Calvopina M, Uezato H, Gomez E, Korenaga M, Nonaka S, Hashiguchi Y 2004. Leishmaniasis recidiva cutis due to Leishmania (Viannia) panamensis in subtropical Ecuador. Inter J Dermatol 43: 659-663.

Census 2001. VI Censo de Poblacion y V de Vivienda. Instituto Nacional de Estadisticas y Censos, Ecuador.

Chico M, Guderian RH 1989. Caracteristicas fotograficas de las leishmaniasis en el Ecuador. Rev Med Vozandes 3: 5666.

Chico ME, Guderian RH, Cooper PJ, Armijos RX Grogl M 1995. Evaluation of a direct immunofluorescent antibody (DIFMA) test using Leishmania genus-specific monoclonal antibody in the routine diagnosis of cutaneous leishmaniasis. Rev Soc Bras Med Trop 28: 99-103.

Cooper P, Guderian R, Paredes W, Daniels R, Perera D, Espinel M, Valdez M, Griffin G 1996. Bartonellosis in Zamora Chinchipe province in Ecuador. Trans R Soc Trop Med Hyg 90: 241-243.

Cupolillo E, Grimaldi Jr G, Momen H 1994. A general classification of New World Leishmania using numerical zymotaxonomy. Am J Trop Med Hyg 50: 296-311.

Davidson RN, Yardley V, Croft SL, Konecny P, Benjamin N 2000. A topical nitric oxide-generating therapy for cutaneous leishmaniasis. Trans R Soc Trop Med Hyg 94: 319-322.

Davies CR, Reithinger R, Campbell-Lendrum D, Feliciangeli D, Borges R, Noris Rodriguez 2000. The epidemiology and control of leishmaniasis in Andean countries. Cad Saúde Pública 16: 925-950.

De Brujin MHL, Labrada LA, Smyth AJ, Santrich C, Barker DC 1993. A comparative study of diagnosis by the PCR and by current clinical methods using biopsies from Colombian patients with suspected leishmaniasis. Trop Med Parasitol 44: 201-207.

Dereure J, Espinel I, Barrera C, Guerrini F, Martini A, Echeverria R, Guderian RH, Le Pont F 1994. Leishmaniasis in Ecuador. 4. Natural infestation of the dog by Leishmania panamensis. Ann Soc Belg Med Trop 74: 29-33.

Desjeux P 2001. The increase in risk factors for leishmaniasis worldwide. Trans R Soc Trop Med Hyg 95: 239-243.

Dujardin JP, Le Pont F, Cruz M, Tarrieu LF, Guderian RH, Echeverria R, Tibayrenc M 1996. Cryptic speciation in Lutzomyia (Nyssomyia) trapidoi (Diptera: Psychodidae) detected by multilocus enzyme electrophoresis. Am J Trop Med Hyg 54: 42-45.

Fernandez T 1990. Paracoccidiodiomicosis. In Texto de Medicina Tropical, Ed. Universidad de Guayaquil, Ecuador, p. 386388.

Furuya M, Akimaru Y, Mimori T, Shiraishi M, Gomez EA, Nonaka S, Hashiguchi Y 1997. Identification of species of Ecuadorian Leishmania isolates by ELISA using monoclonal antibodies. In Studies on New World Leishmaniasis and its Transmission with Particular Reference to Ecuador. Kochi 
Japan. Res Rep Series 5: 11-19.

Furuya M, Motonari S, Akimaru Y, Mimori T, Gomez EA, Hashiguchi Y 1998. Natural infection of Lutzomyia hartmanni with Leishmania (V.) equatorensis in Ecuador. Parasitol Internat 47: 121-126.

Galati EA, Caceres AG, Le Pont F 1995. Description of Lutzomyia (Pifanomyia) robusta n.sp. (Diptera, Psichodidae, Phlebotominae) from Peruvian Equadorean interandean areas. Rev Saúde Pública 29: 89-99.

Garcia W, Gomez EA, Hashiguchi Y 1997. Cutaneous leishmaniasis in El Carmen, province of Manabi, Ecuador. In Studies on New World Leishmaniasis and its Transmission with Particular Reference to Ecuador. Kochi Japan. Res Rep Series 5: 88-93.

Gomez EA, Hashiguchi Y 1991. Monthly variation in natural infection of the sandfly Lu. ayacuchensis with L. mexicana in an endemic focus in the Ecuadorian Andes. Ann Trop Med Parasitol 85: 407-411.

Gomez EA, Hosokawa A, Maruno M, Nonaka S, Suguri S, Hashiguchi Y 1997. Further studies on the oral treatment of cutaneous leishmaniasis with antimalarial drug mefloquine (Mephaquin $\left.{ }^{\circledR}\right)$ in Ecuador. In Studies on New World Leishmaniasis and its Transmission with Particular Reference to Ecuador. Kochi, Japan. Res Rep Series 5: 102-107.

Gomez EA, Katakura K, Matsumoto Y, Nonaka S, Mimori T, Furuya M, Hashiguchi Y 1994. Further epidemiological studies of Andean leishmaniasis in Huigra. In Studies on New World Leishmaniasis and its Transmission with Particular Reference to Ecuador. Kochi, Japan. Res Rep Ser 4: 71-84.

Grimaldi Jr G, Kreutzer R, Hashiguchi Y, Gomez E, Mimori T, Tesh R 1992. Description of Leishmania equatorensis sp. n. (Kinetoplastida:Trypanosomatidae), a new parasite infecting arboreal mammals in Ecuador. Mem Inst Oswaldo Cruz 87: 221-228.

Guderian RH, Chico ME, Rogers MD, Pattishall KM, Grogl M, Berman JD 1991. Placebo controlled treatment of Ecuadorian cutaneous leishmaniasis. Am J Trop Med Hyg 45: 9297.

Hashiguchi Y, Gomez EA 1991. Review of leishmaniasis in Ecuador. Bull PAHO 25: 64-76.

Hashiguchi Y, Gomez EA, de Coronel VV, Mimori T, Kawabata M 1985. Leishmania isolated from wild mammals caught in endemic areas of leishmaniasis in Ecuador. Trans $R$ Soc Trop Med Hyg 79: 120-121.

Hashiguchi Y, Gomez EA, de Coronel VV, Mimori T, Kawabata M 1985. Natural infections with promastigotes in manbiting species of sandflies in leishmaniasis-endemic areas of Ecuador. Am J Trop Med Hyg 34: 440-446.

Hashiguchi Y, Gomez E, de Coronel VV, Mimori T, Kawabata M, Furuya M, Nonaka S, Takaoka H, Alexander JB, Quizhpe AM, Grimaldi Jr G, Kreutzer RD, Tesh RB 1991. Andean leishmaniasis in Ecuador caused by infection with Leishmania mexicana and L. major-like parasites. Am J Trop Med Hyg 44: 202-217.

Hashiguchi Y, Gomez EA, Quizhpe A 1990. Autochthonous Andean leishmaniasis from the Ecuadorian Andes. In Studies on New World Leishmaniasis and its transmission, with particular reference to Ecuador. Kochi, Japan. Res Rep Series 2: 126-139.

Hashiguchi Y, Gomez E, Vera V, Mimori T, Kawabata M 1987. Leishmaniasis in different altitudes on Andean slope of Ecuador. Jap J Trop Med Hyg 15: 7-15.

Hendrickx EP, Agudelo SP, Munoz DL, Puerta JA, Velez BID 1998. Lack of efficacy of mefloquine in the treatment of New World cutaneous leishmaniasis in Colombia. Am J Trop Med Hyg 59: 889-892.
Hosokawa A, Maruno M, Takamiyagi A, Nonaka S, Gomez EA, Hashiguchi Y 2001. Differential diagnosis of cutaneous leishmaniasis in endemic areas of Ecuador. In Studies on New World leishmaniasis and its transmission with particular reference to Ecuador. Kochi, Japan. Res Rep Ser 6: 5868.

Hosokawa A, Paredes D, Nonaka S, Gomez E, Hashiguchi Y 1994. Dermatological survey in rural areas endemic for leishmaniasis and urban areas of Ecuador. In Studies on New World Leishmaniasis and its Transmission, with Particular Reference to Ecuador. Kochi, Japan. Res Rep Ser 4: 118123.

Katakura K, Kawazu SI, Sanjyoba C, Naya T, Matsumoto Y, Ito M, Nagakura K, Aikawa M, Hashiguchi Y 1998. Leishmania mini-exon gene for molecular epidemiology of leishmaniasis in China and Ecuador. Tokai J Exp Clin Med 23: 393-399.

Katakura K, Matsumoto Y, Gomez EA, Furuya M, Hashiguchi Y 1993. Molecular karyotype characterization of Leishmania panamensis, L. mexicana and L. major-like parasites: agents of cutaneous leishmaniasis in Ecuador. Am J Trop Med Hyg 48: 707-715.

Katakura K, Mimori T, Furuya M, Uezato H, Nonaka S, Gomez EA, Hashiguchi Y 2003. Identification of Endotrypanum sp. from a sloth, a squirrel and Lutzomyia sandflies in Ecuador by PCR and sequencing of the mini-exon gene. $J$ Vet Med Sci 65: 649-653.

Krause G, Kroeger A 1994. Topical treatment of American cutaneous leishmaniasis with paromomycin and methylbenzethonium chloride: a clinical study under field conditions in Ecuador. Trans R Soc Trop Med Hyg 88: 92-94.

Laguna-Torres VA, Silva CA, Correia D, Carvalho EM, Magalhaes AV, Macedo V de O 1999. Mefloquine in the treatment of cutaneous leishmaniasis in an endemic area of L. (V.) braziliensis. Rev Soc Bras Med Trop 32: 529-532.

Lainson R 1983. The American leishmaniasis: some observations on their ecology and epidemiology. Trans $R$ Soc Trop Med Hyg 77:569-596.

Lazo RF, Hashiguchi Y 1994. Generalized cutaneous leishmaniasis: parasitologically confirmed case in Ecuador. In Studies on New World Leishmaniasis and its Transmission, with Particular Reference to Ecuador. Kochi, Japan. Res Rep Ser 4: 93-98.

Le Pont F, Barrera C, Caceres AL, Galati EA, Jarra O, Riofrio AR, Mouchet J, Echeverria R, Guderian R 1994c. Leishmaniasis in Ecuador. 6. Epidemiological and entomological note on the focus of leishmaniasis in Zumba. Ann Soc Belg Med Trop 74: 43-49.

Le Pont F, Leon R, Guerrini F, Gantier JC, Mouchet J, Echeverria R, Guderian RH 1994b. Leishmaniasis in Ecuador. 3. Lutzomyia trapidoi, vector of L. panamensis. Ann Soc Belg Med Trop 74: 23-28.

Le Pont F, Leon R, Mouchet J, Echeverria R, Guderian RH 1994a. Leishmaniasis in Ecuador. 2. Man/vector contacts in leishmaniasis: The case of Lu. trapidoi and Lu. gomezi. Ann Soc Belg Med Trop 74: 13-21.

Leon LA 1957. Leishmanias y Leishmaniasis, Ed. Universitaria, Quito, Ecuador, 173 pp.

Lopez M, Inga R, Cangalaya M, Echevarria J, Llanos-Cuentas A, Orrego C, Arevalo J 1993. Diagnosis of Leishmania using the polymerase chain reaction: a simplified procedure for field work. Am J Trop Med Hyg 49: 348-356.

Lopez-Jaramillo P, Ruano C, Rivera J, Teran E, Salazar-Irigoyen R, Esplugues JV, Moncada S 1998. Treatment of cutaneous leishmaniasis with nitric-oxide donor. Lancet 351: 11761177. 
Luyo-Acero GE, Uezato H, Oshiro M, Takei K, Kariya K, Katakura K, Gomez-Landires E, Hashiguchi Y, Nonaka S 2004. Sequence variation of the Cytochrome $b$ gene of various human infecting members of the genus Leishmania and their phylogeny. Parasitology 128: 483-491.

Matsumoto T, Hashiguchi Y, Gomez EA, Calvopina MH, Nonaka S, Saya H, Mimori T 1999. Comparision of PCR results using scrape/exudates, syringe-sucked fluid and biopsy samples for diagnosis of cutaneous leishmaniasis in Ecuador. Trans R Soc Trop Med Hyg 93: 606-607.

Mimori T, Grimaldi Jr G, Kreutzer RD, Gomez EA, McMahonPratt D, Tesh RB, Hashiguchi Y 1989. Identification using isoenzyme electrophoresis and monoclonal antibodies of Leishmania isolated from humans and wild animals of Ecuador. Am J Trop Med Hyg 40: 154-158.

Mimori T, Matsumoto T, Calvopina MH, Gomez EA, Saya H, Katakura K, Nonaka S, Shamsuzzaman SM, Hashiguchi Y 2002. Usefulness of sampling with cotton swab for PCRdiagnosis of cutaneous leishmaniasis in the New World. Acta Trop 81: 197-202.

Mimori T, Sasaki J, Nakata M, Gomez EA, Uezato H, Nonaka S, Hashiguchi Y, Furuya M, Saya H 1998. Rapid identification of Leishmania species from formalin-fixed biopsy samples by polymorphism-specific polymerase chain reaction. Gene 210: 179-186.

Mimori T, Sud R, Gomez LE, Hashiguchi Y 1992. A seroepidemiological survey of canines in an area endemic for Andean leishmaniasis in Ecuador. In Studies on New World Leishmaniasis and its Transmission with Particular Reference to Ecuador. Res Rep Series 3: 45-48.

Momen H, Pacheco RS, Cupolillo E, Grimaldi G Jr 1993. Molecular evidence for the importation of Old World Leishmania into the Americas. Biol Res 26: 249-255.

Mori M, Asare C, Terabe M, Katakura K, Nanaka S, Gomez EA, Hashiguchi Y, Matsumoto Y 1994. Serological survey of the domestic dogs in leishmaniasis endemic areas of Ecuador. In Studies on New World Leishmaniasis and its Transmission with Particular Reference to Ecuador. Kochi, Japan. Res Rep Series 4: 64-70.

Nonaka S, Gomez EA, Hashiguchi Y 1990. A comparative study of cutaneous changes of leishmaniasis patients from highland and lowland Ecuador. In Studies on New World Leishmaniasis and its Transmission with Particular Reference to Ecuador. Kochi, Japan. Res Rep Series 2: 150-161.

Nonaka S, Gomez EA, Sud R, Alava JJ, Katakura K, Hashiguchi Y 1992. Topical treatment for cutaneous leishmaniasis in Ecuador. In Studies on New World Leishmaniasis and its Transmission, with Particular Reference to Ecuador. Kochi, Japan. Res Rep Series 3: 115-124.

Nonaka S, Hosokawa A, Maruno M, Sud R, Gomez EA, Hashiguchi Y 1997. Clinical survey of cutaneous leishmaniasis in Ecuador for 5 years. In Studies on New World Leishmaniasis and its Transmission with Particular Reference to Ecuador. Kochi, Japan. Res Rep Series 5: 82-87.
Osorio LE, Castillo CM, Ochoa MT 1998. Mucosal leishmaniasis due to Leishmania (Viannia) panamensis in Colombia. Clinical characteristics. Am J Trop Med Hyg 59: 49-52.

Pratlong F, Deniau M, Darie H, Eichenlaub S, Proll S, Garrabe E, le Guyadec T, Dedet JP 2002. Human cutaneous leishmaniasis caused by Leishmania naiffi is wide-spread in South America. Ann Trop Med Parasitol 96: 781-785.

Reithinger R, Lambson B, Barker D, Davies C 2000. Use of PCR to detect Leishmania (Viannia) spp. in dog blood and bone marrow. J Clin Microbiol 38: 748-751.

Reyna E, de Aroca M, Castillo A, Gomez E, Nonaka S, Katakura K, Furuya M, Hosokawa A, Hashiguchi Y 1994. Diffuse cutaneous leishmaniasis: The first report of a parasitologically confirmed case in Ecuador. In Studies on New World Leishmaniasis and its Transmission with Particular Reference to Ecuador. Kochi, Japan. Res Rep Series 4: 85-92.

Rodriguez JD 1974. Lecciones de Parasitologia Humana: Genero Leishmania, 5th ed., Universidad de Guayaquil, Ecuador, p. 170-185.

Takaoka H, Gomez E, Alexander Jr B, Hashiguchi Y 1990. Further studies on the natural infections of Ecuadorian sandflies. In Studies on New World Leishmaniasis and its Transmission with Particular Reference to Ecuador. Kochi, Japan. Res Rep Series 2: 40-48.

Uezato H, Hagiwara K, Hosokawa A, Maruno M, Nonaka S, Oshiro M, Nakashima Y, Furuya M, Hashiguchi Y 1998. Comparative studies of the detection rates of Leishmania parasites from formalin, ethanol-fixed, frozen human skin specimens by PCR and Southern blotting. J Dermatol 25: 623-631.

Uezato H, Maruno M, Khaskhely NM, Nonaka S, Oshiro M, Kariya K, Katakura K, Mimori T, Gomez EA, Shamsuzzaman SM, Hashiguchi Y 2001. Detection of Endotrypanum using PCR and Southern blotting. In Studies on New World Leishmaniasis and its Transmission with Particular Reference to Ecuador. Kochi Japan. Res Rep Series 6: 17-25.

Weigel MM, Armijos RX 2001. The traditional and conventional medical treatment of cutaneous leishmaniasis in rural Ecuador. Rev Panam Salud Publica 10: 395-404.

Weigel MM, Armijos RX, Racines RJ, Zurita C, Izurieta R, Herrera E, Hinojosa E 1994. Cutaneous leishmaniasis in Subtropical Ecuador: popular perceptions, knowledge, and treatment. Bull PAHO 28: 142-155.

Weigel MM, Armijos RX, Zurita C, Racines J, Reddy A, Mosquera J 1995. Nutritional status and cutaneous leishmaniasis in rural Ecuadorian children. J Trop Ped 41: 22-28.

Yamasaki H, Agatsuma T, Pavon B, Moran M, Furuya M, Aoki T 1994. Leishmania major-like parasite a pathogenic agent of cutaneous leishmaniasis in Paraguay. Am J Trop Med Hyg 51: 749-757.

Young DG, Rogers TE 1984. The phlebotomine sand fly fauna (Diptera: Psychodidae) of Ecuador. J Med Entomol 21: 597 611. 